\title{
Trends in productivity of crops, fallow and rangelands in Southwest Niger: Impact of land use, management and variable rainfall
}

\author{
Pierre Hiernaux $^{\mathrm{a}, *}$, Augustine Ayantunde ${ }^{\mathrm{b}}$, Adamou Kalilou $^{\mathrm{c}}$, Eric Mougin ${ }^{\mathrm{a}, \mathrm{d}}$, Bruno Gérard ${ }^{\mathrm{e}}$, \\ Frédéric Baup ${ }^{\mathrm{a}}$, Manuela Grippa ${ }^{\mathrm{a}}$, Bakary Djaby ${ }^{\mathrm{f}}$ \\ ${ }^{a}$ CESBIO, 18 Avenue E. Belin b.p.i. 2801, 31401 Toulouse Cedex 9, France \\ ${ }^{\mathrm{b}}$ ILRI, ICRISAT Research Station, Samanko, B.P. 320, Bamako, Mali \\ ${ }^{\mathrm{C}}$ ILRI, ICRISAT Sahelian Centre, B.P. 12404, Niamey, Niger \\ ${ }^{\mathrm{d}}$ IRD, B.P. 2528, Hippodrome 238 Rue 234, Bamako, Mali \\ e ILRI, P.O. Box 5689, Addis Ababa, Ethiopia \\ ${ }_{\mathrm{f}}^{\mathrm{E}}$ Environment Sciences and Management Dpt., Univ. of Liège, Arlon, Belgium
}

\section{A R T I C L E I N F O}

Available online $\mathrm{xxxx}$

\section{Keywords:}

Sahel

Vegetation dynamics

Land use

Millet crops

Fallows

Vegetation growth modelling

\begin{abstract}
S U M M A R Y
To document trends in land use and herbaceous production, 71 field sites sampled among cropped fields, fallow fields and rangelands in the Fakara region (Niger) were monitored from 1994 to 2006. The overall trend in land use confirmed the historical increase of the cropped areas since mid 20th century, at an annual rate of $2 \%$ from 1994 to 2006. This trend is the result of changes in the relative extent of fields permanently cropped and fields under shifting cultivation, and for the latter, the relative proportion of short ( 3 years) and long (10 years) duration fallows. Type of land use together with topography and soil type determine the herbaceous production and the resulting yield measured towards the end of the wet season. The variation in site yields between years is of the same order of magnitude as the variation in yields between sites within a year. There is an overall decreasing trend in site yields by $5 \%$ annually from 1994 to 2006 that is not explained by variations in rainfall. The decreasing trend is observed on fields under shifting cultivation, fallowed fields and rangelands, although not all sites are equally affected. Causes are likely to be multiple which might include changes in land use, decline of soil fertility and increased grazing pressure. Indeed, the remaining rangelands on marginal land and the fallows still accessible to livestock are subject to such a heavy grazing during the rainy season that the herbaceous standing mass measured at the end of the season reflects poorly the actual production. After the two first years of cropping, the herbaceous yield in fields under shifting cultivation with no fertilisation is negatively affected by the number of successive years of cropping. Moreover, clearing fallow after a decreasing number of years affects the mean herbaceous yield of fallowed fields by reducing the contribution of more productive old fallows. Changes in land use, grazing pressure and soil fertility also triggered changes in species composition with a strong reduction in diversity from rangelands to fallows, and again from fallows to cropland weeds. No correlations was found however between productivity and species composition. Cumulative rainfall does not explain between site or between year deviations in herbaceous yield even when sites are sorted by land use type or by soil type in the case of fallow and rangelands. Simulated production calculated with the STEP model does not explain herbaceous yields much better even when sites are grouped by land use and soil type. However, relative changes of herbaceous yields are reasonably predicted on sites that remained fallowed and were not heavily grazed for at least four consecutive years.
\end{abstract}

(c) 2009 Elsevier B.V. All rights reserved.

\section{Introduction}

Land cleared for cropping and the resulting area cropped increased in the Fakara region, in Southwest Niger, during the second half of the 20th century (Loireau, 1998; Hiernaux and Turner,

\footnotetext{
* Corresponding author. Tel.: +33 0561558537; fax: +33 0561558500.

E-mail address: pierre.hiernaux@cesbio.cnes.fr (P. Hiernaux).
}

2002) and this trend is observed more widely in the Sahel belt across Africa (Amissah-Arthur et al., 2000; Olsson et al., 2005). This strong land use dynamics followed the demographic upsurge of the rural population and the settlement of the Fulani pastoralists (Guengant et al., 2002). The expansion of the cropped area, including on marginal land, and the reduction of fallow duration not accompanied by an increase in fertiliser input has contributed to the impoverishment of soil fertility by accelerating organic matter 
mineralization thereby enhancing nutrient exports (Schlecht et al., 2004). The expansion of the area cropped also enhanced soil erosion by wind in the dry season (Bielders et al., 2002) and by run-off water during the rainy season (Leblanc et al., 2008). The increased volume of run-off water, especially from the hard pan plateaus, expanded and deepened the web of gullies (Estèves and Lapetite, 2003), amplified the rate of soil loss on the slopes while sedimentation and flooding were enhanced in the lowlands and ponds contributing to increased aquifer recharge (Favreau, 2000).

Livestock population also increased although at a lower rate after large losses following the major droughts (Turner, 2000). This increase in livestock population together with the reduction of livestock mobility linked to settlement of Fulani pastoralists and to crop area expansion, aggravated the shortage of quality grazing resources for livestock in the late dry and early wet season (Schlecht et al., 2006; Ayantunde et al., 2008). The increase in livestock population also severely increased the grazing pressure on the rangeland especially during the growing season when livestock are excluded from cropland (Turner et al., 2005). High grazing pressure during the growing season affects herbage production and enhances soil erosion through reduced herbaceous cover and loosening of the soil surface through trampling (Hiernaux et al., 1999). Although a large fraction of the nutrients ingested by livestock is recycled within the landscape, the overall negative balance of nutrient uptake and recycling through excretions contributes to a decline in soil fertility, except on the small fraction of the landscape that benefits from large livestock manure deposition (Schlecht et al., 2004).

Moreover, rainfall declined from the late sixties with major droughts occurring in 1972-73 and again in 1983-84. Rainfall remained below the averages established on the first half of the century until 1994 from which they maintained close to that average or below (Balme et al., 2006). Concerns raised by the severe impact of these droughts on the population, rural economy and on the environment fuelled a series of international research projects in the Fakara region including TropSoils (1991), EPSAT-SG ('Estimation des Précipitations par Satellite', Lebel et al., 1997), HAPEX-Sahel ('Hydrology Atmosphere Pilot Experiment', Goutorbe et al.,1997), research on farming systems by the consortium ILRI-ICRISAT-INRAN ('International Livestock Research Institute', 'International Crop Research Institute for the Semi-Arid Tropics', and 'Institut National de la Recherche Agronomique au Niger' respectively), and AMMA('African Monsoon Multidisciplinary Analysis') under which this work was conducted (Redelsperger et al., 2006; Cappelaere et al., this issue). Large data sets on climate, hydrology, soil, vegetation, crop and farming systems were established by these projects. Among them, EPSAT and the ICRISAT led projects developed a dense web of automatic and manual rain gauges that provide local daily rainfall data at a spatial resolution of a couple of kilometres over the Fakara district. In the same district ILRI led a detailed land use mapping and seasonal monitoring of a set of representative crop, fallow and rangeland sites from 1994 to 2006 (Fig. 1) in order to assess fodder resources and their use (Hiernaux and Ayantunde, 2004).

The first objective of this paper is to assess the trends in herbaceous production on the crop, fallow and rangeland sites and verify to what extend they are explained by rainfall and soil moisture regime. Indeed, the first hypothesis is that herbaceous production is driven by cumulative annual rainfall recorded at each site (Le Houérou, 1984). Because the soil moisture regime is poorly related to cumulative rainfall (Rockström and de Rouw, 1997) an alternative hypothesis is that herbaceous growth simulation using a daily time step water balance model better explains yields than cumulative rainfall (Mougin et al., 1995). In addition, an overall decline in soil fertility is expected from the changes in land use, cropping and livestock management practices observed in the Fakara region over half a century (de Rouw, 1998). A third alternative hypothesis is that this decline in soil fertility in turns affects herbaceous productivity beyond the fluctuations due to variations in rainfall. Changes in land use, grazing pressure and soil fertility also triggered changes in herbaceous species composition (Hiernaux, 1998). Another objective of this paper is to document these changes, and discuss their possible impact on herbaceous productivity.

\section{Materials and methods}

\section{The Fakara study area}

The study area covers $500 \mathrm{~km}^{2}$ between latitude North $13^{\circ} 20^{\prime}-$ $13^{\circ} 35^{\prime}$ and longitude East $2^{\circ} 35^{\prime}-2^{\circ} 52^{\prime}$, and extends over three agro-pastoral territories (Fig. 1 ) all included within the Fakara district. Fakara stands on 150-200 m thick horizontal sandstone deposits of the 'continental terminal' series that explains the sandiness of the derived soils and their poor chemical fertility (TropSoils, 1991). Topography, geomorphology and soils are inherited from a long history of climate fluctuations from hyper-arid to sub-humid during the quaternary (d'Herbes and Valentin, 1997). Soils differ across landscape but all tend to have low organic matter content and weak structure ( TropSoils, 1991). The high prevalence of intense rainfall events contributes to higher rates of soil crusting and run-off than would be expected from the sandy texture of most soils (Casenave and Valentin, 1992). The climate of Fakara is a typical inland semi-arid tropical climate with an average annual rainfall at Niamey (70 km to the West) of $560 \mathrm{~mm}$ (1905-1989) and of $495 \mathrm{~mm}$ only from 1968 to 1989 (Lebel et al., 1997). Total rainfall at a given site varies from year to year with a coefficient of variation between $25 \%$ and 30\% (Le Barbé and Lebel, 1997). The rainy season lasts $4-5$ months, peaking in August, but the spatial and temporal distribution of rains during the rainy season are highly variable. Though historically populated by Jerma sedentary farmers (about $2 / 3$ of the total population), the Fakara also harbours a Fulani population (about 1/3) of agro-pastoral farmers that settled mostly following the 70's drought. From their pastoral culture the Fulani households have inherited higher livestock husbandry skills and are in general better endowed in livestock with 5-20 Tropical Livestock Units (TLU) per household. Most Jerma farmers also raise livestock but in more limited number, less than 2 TLU per household except the wealthier households (10\%) who manage 10-15 TLU (Hiernaux and Turner, 2002).

\section{The vegetation survey}

Within the framework of the ILRI led study of crop-livestock interactions in mixed farming systems, vegetation of a set of selected 71 field sites of 2 ha each were monitored between 1994 and 2006 (Table 1). Initially, only 24 cropland and 24 fallow-rangeland sites were sampled across the three agro-pastoral territories of the Fakara to assess and monitor fodder resources. However, as the land use status of some of these sites changed, additional sites had to be included to keep the sample balanced between cropland and fallow-rangeland, and finally the survey covered 71 sites. The land use status was recorded on the surveyed sites and the land use history of the additional sites was completed a posteriori based on farmer's information on a total of 65 sites from 1994 to 2001, 67 in 2002, 69 in 2003 and 71 from 2004 onwards. The main objective of this monitoring is to assess the seasonal and inter-annual changes in fodder resources for livestock. Land use is very dynamic in Fakara (Loireau, 1998) and with the exception of three rangelands sampled on non arable soils and five fields that remained cropped throughout, most of the sites have changed land use, often several times, since the onset of the survey in 1994. These land use changes have been monitored and are used to characterise the pattern of crop-fallow rotations. 


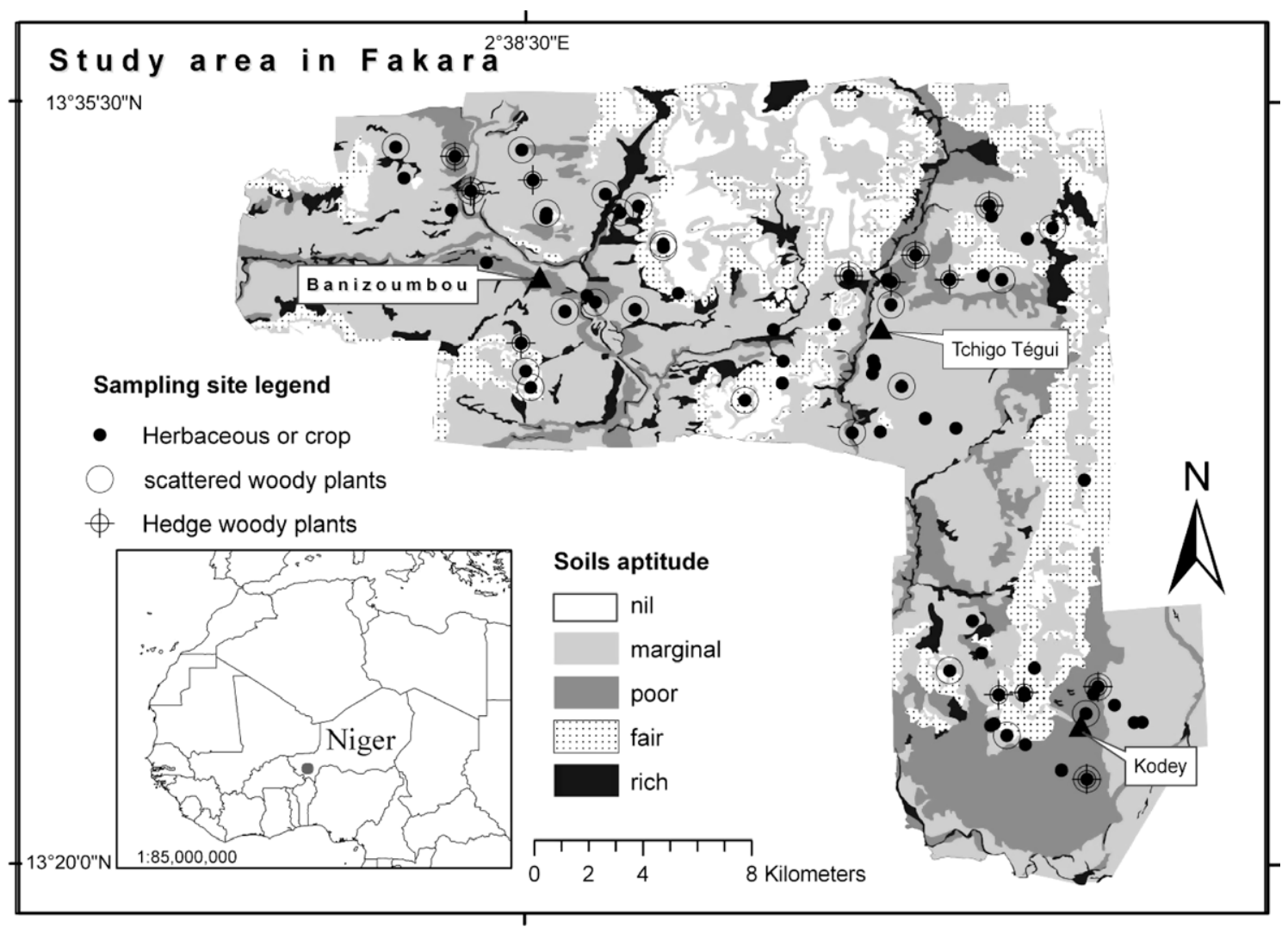

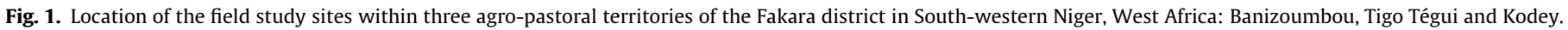
The five class of soil aptitude to cropping are based on geomorphology, soil texture and soil surface features (Hiernaux and Ayantunde, 2004).

Table 1

Characteristics of the topography, land forms, soil types and soil properties of field sites sampled in Fakara.

\begin{tabular}{|c|c|c|c|c|c|c|}
\hline Topography & Land form & Top soil texture ${ }^{*}$ & Soil type (FAO) & Water infiltration & Soil fertility & Number of sites \\
\hline \multirow[t]{5}{*}{ Plateau } & Dune on top of iron pan & $\mathrm{S}$ & Ferralic arenosol & Medium & Fair & 2 \\
\hline & Thin sand on iron pan & $\mathrm{S}$ & Ferralic arenosol & Low & Poor & 5 \\
\hline & Iron pan outcrop & $\mathrm{R}, \mathrm{G}, \mathrm{LS}$ & Skeletic leptosol & Very low & Poor & 2 \\
\hline & Thin loam on iron pan & LS & Ferralic arenosol & Low & Fair & 3 \\
\hline & Rock cliff at plateau edge & $\mathrm{R}, \mathrm{G}, \mathrm{LS}$ & Skeletic leptosol & Very low & Poor & 1 \\
\hline \multirow[t]{3}{*}{ Up-slope } & Thick sand deposits & $\mathrm{S}$ & Ferralic arenosol & Medium & Fair & 10 \\
\hline & Erosion surface, gullies & LS, G & Skeletic leptosol & Low & Fair & 3 \\
\hline & Colluvion fan & S, LS & Cambic arenosol & High & Fair & 2 \\
\hline \multirow[t]{5}{*}{ Mid- and down-slope } & Dune on top of flats & S & Arenic lixisol & Medium & Fair & 9 \\
\hline & Thin sand on flats & $\mathrm{S}, \mathrm{G}$ & Arenic lixisol & Low & Poor & 12 \\
\hline & Thin loam on flats & LS, G & Ferralic arenosol & Low & Fair & 7 \\
\hline & Erosive surfaces & G, LS & Leptic lixisol & Low & Fair & 7 \\
\hline & Thick colluvion & LS, S & Arenic cambisol & Medium & Poor & 3 \\
\hline \multirow[t]{6}{*}{ Valley } & River bed \& banks & $\mathrm{S}$ & Arenic lixisol & Medium & Poor & 1 \\
\hline & Minor streams & LS & Arenic lixisol & Medium & Poor & 1 \\
\hline & Fossil alluvial plain & $\mathrm{S}$ & Gleyic arenosol & Low & Poor & 1 \\
\hline & Fossil levees & LS & Gleyic arenosol & Low & Poor & 1 \\
\hline & Fossil river bed & LS, CL & Arenic gleysol & High & Fair & 1 \\
\hline & River bed & $\mathrm{LS}, \mathrm{CL}$ & Arenic gleysol & High & Fair & 1 \\
\hline
\end{tabular}

$\mathrm{S}=$ sands, $\mathrm{R}=$ Rocks or Iron pan, $\mathrm{G}=$ gravels, $\mathrm{LS}=$ loamy sands, $\mathrm{Cl}$ = clayed loams.

Observations and measurements on the vegetation were conducted at the end of the growing season (October) providing an estimate of the seasonal herbaceous yield. From 1994 to 1996 and again in 1998, measures were also performed at mid-dry season (February) and at the end of the dry season (June) in order to assess the rate of degradation of the herbaceous layer and resulting fodder resources during the dry season. At each date, the herbaceous standing mass is measured destructively in 12 plots of $1 \mathrm{~m}^{2}$ randomly distributed along a fixed $200 \mathrm{~m}$ transect and sam- pled in three preset strata defined by the apparent bulk of the herbaceous vegetation. Three of the plots are sampled in the 'low' and in the 'high' stratum, and the six others in the 'median' stratum, while herbaceous cover and mass are set to zero in 'bare soil' stratum (details on the sampling method in Hiernaux et al., this issue). The relative areas occupied by the strata at each site are estimated by counting their occurrence in a $1 \mathrm{~m}$ wide band along the $200 \mathrm{~m}$ transect, these frequencies being used to weight the mean herbaceous cover and mass per stratum. Site species composition is 
established by listing all species observed in each of the 12 sampled plots, and visually estimating their cover within each plot. Average species cover is calculated by stratum and then weighted by the stratum frequency to assess species contribution to site plant cover.

In cropped fields, weeds are also sampled in $1 \mathrm{~m}^{2}$ plots, with species listed and destructive standing mass measurements done for each of 10 plots placed every $10 \mathrm{~m}$ along the $100 \mathrm{~m}$ axis. The mass of the crop stalks is estimated by determining the density of crop plants in the selected site and sub-sampling ten of these plants. The millet crop density is estimated following the Point Centred Quadrant (PCQ) method, i.e. by measuring the distance of the nearest plant to sampling points every $10 \mathrm{~m}$ along the axis (not parallel to hill lines), within four quadrants defined by the axis and the line perpendicular to the axis at that point. These distances are averaged at each point $(\bar{d})$. The cropped plant density $(D, \#$ $\left.\mathrm{ha}^{-1}\right)$ is estimated by the inverted square of that mean $(\bar{d}$ in meter $)$ multiplied by the area of reference $\left(1 \mathrm{ha}=10000 \mathrm{~m}^{2}\right)$ :

$D_{1}=\frac{10000}{\bar{d}^{2}}($ Cottam and Curtis, 1956).

Because cropped plants are more or less regularly distributed (hoe cultivated) this density algorithm is preferred to a more recently developed one (Pollard, 1971) following published validation tests (White et al., 2008). In the case of cereal crops, millet and sorghum, sampled plants are characterised by the number of tillers separated into three categories: the short (less than $50 \mathrm{~cm}$ high) tillers that remain vegetative, the tall (more than $150 \mathrm{~cm}$ high) tillers with fully developed panicles, and the intermediate class (50-150 cm high) with aborted or not fully developed panicle. The stems and leaves of the 10 sampled plants are harvested separately by tiller class, and leaves were further subdivided into blade and sheath (in 1994-1998 only). Grain yields are indirectly estimated based on harvest index measured in a subsample of fields within each field type. Plant taxonomy follows the Flora of Tropical West Africa (Hutchinson and Dalziel, 1954-1972).

\section{Land use mapping}

To upscale land use from site observations, land use was mapped over the three pastoral territories. Because of the large inter-annual changes observed of the land use status of fields in Fakara (Loireau, 1998) land use has been mapped repetitively from aerial photos taken in 1994, 1995 and 1996 with a Nikon F3 camera from a small aircraft flying at 1200 feet above ground (Hiernaux and Ayantunde, 2004). Land use types include permanently cropped fields (manured), cropped fields under shifting cultivation, recent fallows (herbaceous), old fallows (bushy) and rangelands. Settlements, roads, cattle paths, drainage lines, water points, field hedges and main trees were also mapped. Besides, the same land use types (plus 'pristine savanna') were mapped by stereoscopic photo-interpretation on existing aerial photos for 1950, 1975 and 1992. Statistics on land use dynamics were generated by overlaying these maps within a Geographic Information System (Hiernaux and Turner, 2002).

\section{Rainfall survey}

Daily rainfall data were collected by manual rain gauges either already setup in the main villages or put in place by ILRI in 1994, or else by ICRISAT (up to 71 rain gauges at field sites in Fakara) since 2000 , located in villages, camps and in ICRISAT experimental fields.

From 2000 to 2006, the network of rain gauges allowed to get rain for each site from the nearest gauge at a mean distance of $1.4 \pm 0.7 \mathrm{~km}$ with a maximum distance of $6 \mathrm{~km}$.

\section{Statistical analysis}

Regressions were established between the herbaceous mass at the end of the growing season and the total rainfall measured at the nearest rain gauge. This was done for all sites per land use type. In the case of rangelands and fallows, regressions were also established for sites grouped by soil types (Table 1). In cropped fields regressions were established for each field type and separately for millet stalk and weed yields. The regressions were established for data collected for the period 1994-2006, and also for the period 2000-2006 during which the web of rain gauges is much denser. All statistical analyses were performed with SAS (SAS, 1987).

\section{Simulating primary production}

The herbaceous production for each site and year was simulated by using the 'Sahelian Transpiration Evaporation and Production', STEP, model (Mougin et al., 1995). The input weather data included daily rainfall, mean maximum and minimum temperatures, potential evapo-transpiration, global radiation, mean water vapour pressure, and mean wind speed. The latitude and longitude coordinates and the altitude were given for each site. Run-off coefficient was set to zero, and the soil of each site was characterised by the depth, sand and clay contents of four horizons $(2,12,32$ and $100 \mathrm{~cm}$ depth) for which the share of the root mass at the maximum herbaceous standing mass was attributed (5\%, 25\%, 60\% and 10\%). The species composition was characterised by the mass proportion of grasses and dicotyledons as well as the mass proportion of species with C3 or C4 photosynthesis types. The model STEP includes two sub-models dealing with plant growth and water fluxes respectively. The plant growth sub-model simulates annual plant germination, photosynthesis, carbohydrate allocation above and below ground, plant growth and senescence. The water flux model simulates plant transpiration and soil evaporation by means of Penman-Monteith equation, and the soil water content is simulated by means of a four layer water bucket model. At a daily time step, plant growth simulation calculates herbaceous canopy height, cover, leaf area index, above and below ground production, green and dead standing masses (Mougin et al., 1995; Tracol et al., 2006). Cumulative production during the growing season simulated by STEP was compared to recorded herbaceous standing mass at the end of the wet season. To reduce the impact of the site specific conditions not taken in account by the STEP model (run-off, soil fertility, grazing pressure) the comparison between simulated production and measured yield was also made considering anomalies, i.e. the differences to the means over the study period, calculated at each site for both simulated production and measured yield.

\section{Results}

\section{Trends in land use from field site monitoring}

The relative frequencies of the land use status of the 65-71 sites observed between 1994 and 2006 were calculated for each year (Fig. 2). When the proportion of sites partially cropped that varies between $10 \%$ and $20 \%$ from year to year is shared equally between cropped and fallowed sites, the frequency of cropped sites increased over the years at a mean annual rate of $2.0 \%$ leading to a total increase by $12.4 \%$ between 1994 and 2006. Conversely, the frequency of fallows decreased at a mean rate of $1.5 \%$ per year and $8.5 \%$ between 1994 and 2006. The frequency of rangelands decreased slightly just because the total number of sites monitored increased from 65 to 71 while the number of sites sampled on non-cultivated soils under rangeland status remained unchanged 


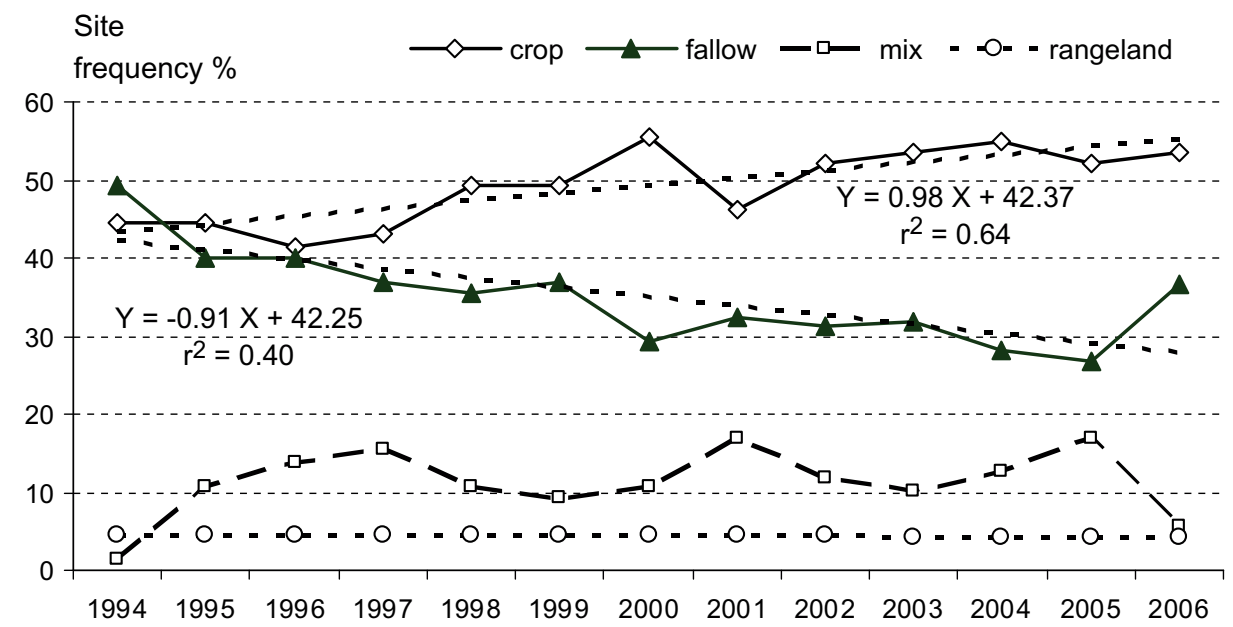

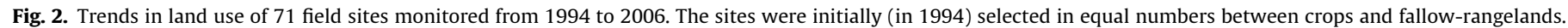
Then some of the sites were became partially cropped and were thus classified as 'mix'.

over the whole period. The average durations of crop and fallow periods completed between 1994 and 2006 were $4.6( \pm 4.0)$ and $4.8( \pm 4.5)$ years, respectively. These averages did not include the crop and fallow cycles that were ongoing in 2006, and are thus biased to the detriment of the longest cycles. When ongoing cycles were included the average durations reached $7.3( \pm 10.5)$ and 8.1 $( \pm 13.5)$ years, respectively. Actually, two main types of cropland can be distinguished: permanently cropped fields and fields under shifting cultivation (Gandah et al., 2003). Permanently cropped fields are generally manured and located close to the villages and camps. They are devoted to staple, using short cycle cultivars under a risk avoiding strategy. Because one year interruption sometimes occurs for agronomic or tenure reasons, the average duration of cropping in permanently cropped field was 9.5

a

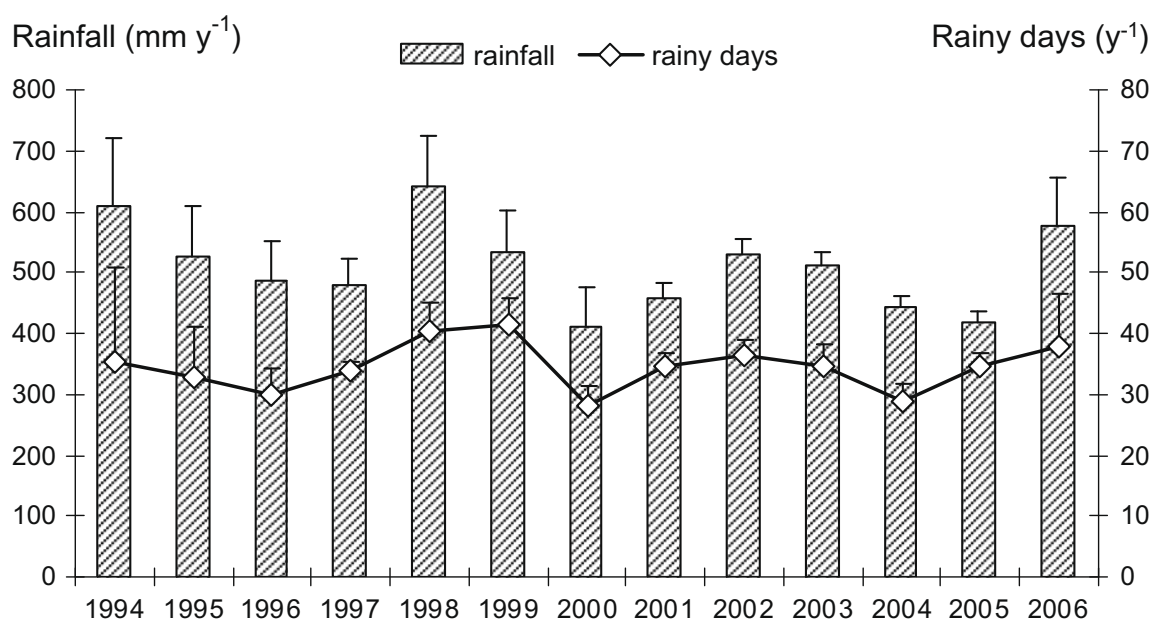

b

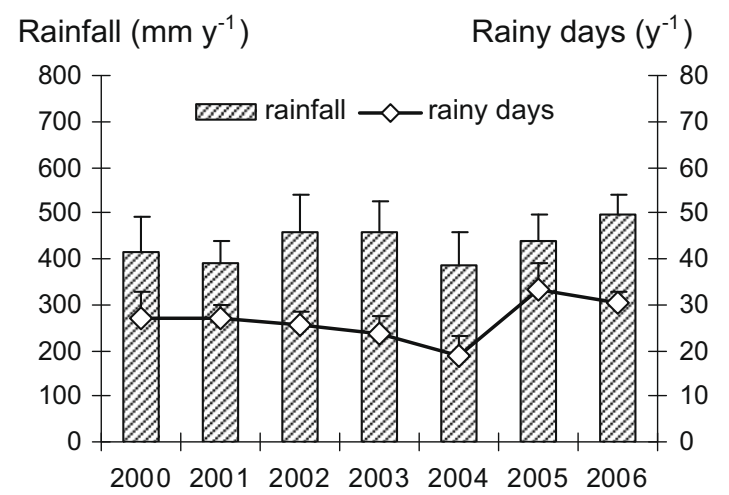

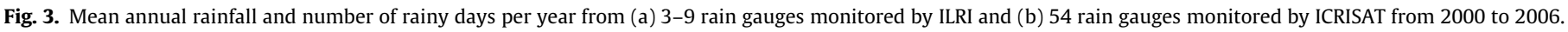
The overall mean rainfall is indicated by a dashed line. 
$( \pm 5.8)$ years. The fields under shifting cultivation are further away from the villages and camps and were cultivated during $3.4( \pm 9.5)$ years on average. These fields are left in fallow in between crop cycles. When the one year crop interruptions are excluded, two types of fallow can also be distinguished by their duration: the short fallows, averaging $3.4( \pm 1.2)$ year duration and the long fallows, averaging $10.8( \pm 5.5)$ year duration.

\section{Land use history at landscape scale}

With the increase of rural population, all Fakara arable land had been cleared for cropping by the late 1980s so that the proportion of land kept as rangelands in 1994 in the three studied agro-pastoral territories only depends on the relative extent of the non-arable hard pan plateaus and surrounding steep slopes (Table 2). In contrast, the relative proportion of land cropped and fallowed varied between the territories: Kodey territory being more extensively cropped than Tigo Tegui and Banizoumbou due to higher population density related to a more ancient settlement controlled by the access to water (Hiernaux and Turner, 2002). In all three territories, the increase in cropped areas between 1950 and 1975 was very fast and was accompanied by an increase of fallowed areas, so that the rate of cropland (crop plus fallow fields) expansion reached $13.5 \%$ per annum. The area cropped still increased between 1975 and 1994 , but by $3.3 \%$ per year only and with no further increase of the fallowed areas.

\section{Variations in rainfall}

Annual rainfall means in Fakara between 1994 and 2006 ranged from 393 to $759 \mathrm{~mm}$ and average $517 \mathrm{~mm}$ ( \pm 102 ) with 35.2 $( \pm 6.8$ ) rainy days (Fig. 3a). Relative to this mean, the years 1994, 1998 and 2006 can be considered 'wet', while the couples 199697, 2000-01 and 2004-05 can be considered 'dry'. There are thus three successive sequences of two 'wet' or 'mean' years followed by two 'dry' years. Mean annual rainfall from the 54 sites monitored from 2000 to 2006 (Fig. 3b) was slightly inferior at $434 \mathrm{~mm}$ $( \pm 76)$ and $26.5( \pm 6.1)$ rainy days, with relatively little variations between yearly means (coefficient of variation 9.1\%). However, rainfall measured in sites, at most $30 \mathrm{~km}$ apart, ranged between a minimum of 297 and a maximum of $602 \mathrm{~mm}$ in the same year (more on the subject in Lebel and Ali, this issue). Such spatial differences in total annual rainfall are in part explained by the large portion of the total rainfall (39\%) due to a few (3.9 \pm 1.6 on average) major rain events (superior to $30 \mathrm{~mm}$ and $44 \pm 7 \mathrm{~mm}$ on average).

\section{Trends in the production of herbaceous vegetation}

Herbaceous yields of crop fields (millet or sorghum stalks plus weeds), fallowed fields and rangelands, averaged $1288 \pm 1010 \mathrm{~kg}$ of Dry Matter (DM) ha ${ }^{-1}$ across years and sites (Fig. 4a). These yields fluctuated widely across years between a minimum of $709 \pm 568 \mathrm{~kg} \mathrm{DM} \mathrm{ha}^{-1}$ in 2000 and a maximum of $1812 \pm 1257$ $\mathrm{kg} \mathrm{DM} \mathrm{ha}^{-1}$ in 1996. Poor yields, less than $1000 \mathrm{~kg} \mathrm{DM} \mathrm{ha}^{-1}$, were recorded in the dry years of 2000 and 2005 but not in those of 1996, 1997, 2001 and 2004. Also a poor yield was recorded in 2003 when rainfall was average. The results suggest that a dry year does not always translate into poor herbaceous yield as observed in 1996. Conversely, a wet year does not necessarily imply high yields as in 2006. In addition, yield trends of fallow and rangelands do not parallel systematically those of croplands. Fallow and rangelands yields were above $1000 \mathrm{~kg} \mathrm{DM} \mathrm{ha}^{-1}$ from 1994 to 1996 and in 2002 but yields were less than $500 \mathrm{~kg}$ in 2000 and 2003, with a slight overall declining trend over the period 1994 2006 (Fig. 4b; $y=636$ Ln (year) $+150 ; r^{2}=0.65$ ). The herbaceous yield of rangelands were very low due to their location on very shallow soils, especially hard pan plateaus. Accounting for large areas of bare soil patches, rangeland yields averaged $221 \pm 141 \mathrm{~kg} \mathrm{DM} \mathrm{ha}^{-1}$. Fallow yields tended to be higher the first year after cultivation, to then stabilised or decreased slightly during the following four years, and may only recover yield capacity in old fallows (Fig. 4c).

High yields were more often observed in croplands than on fallow or rangelands, exceeding $2000 \mathrm{~kg} \mathrm{DM}$ ha from 1994 to 1998, in 2001-2002 and again in 2004 irrespective of rainfall (Fig. 5a). The mean weed yield did not vary much over years if the low value recorded in 1994 (due to late observation) is excluded. Even if the mass of harvested panicles is not included in millet yield (panicles account for $20-25 \%$ of total millet mass), total herbaceous yield from cropland appears generally higher than from fallow or rangeland. Yields on permanently cropped fields that receive manure more or less regularly stand out above that of all other land use types at $2755 \pm 678 \mathrm{~kg} \mathrm{DM} \mathrm{ha}^{-1}$ including $251 \pm 188 \mathrm{~kg} \mathrm{DM} \mathrm{ha}^{-1}$ of weeds. Higher planting density with $9316 \pm 2182$ hills ha $^{-1}$, higher density of tillers per hill at $9.1 \pm 2.2$, larger proportion of tall fertile tillers (43.2 versus $31.5 \%$ in other fields) and slightly heavier tillers (+21.4\%), all contribute to the high crop yields of these permanently cropped fields. However, the relative contribution of leaves to plant mass $(43.3 \pm 3.6 \%)$, and of blades to leaf mass $(57.7 \pm 0.7 \%)$ do not differ between field types. The yields in fields under shifting cultivation vary largely between fields and years so that these cropped fields were stratified each year in three categories depending on crop plant density and size at harvest. Fields with low plant density average $6101 \pm 2122$ hills ha $^{-1}$, while medium density fields average $7400 \pm 1968$ hills ha $^{-1}$, and high density fields average $8730 \pm 3402$ hills ha $^{-1}$. Mean yields of millet stalks ranged from $652 \pm 358 \mathrm{~kg} \mathrm{DM} \mathrm{ha}^{-1}$ in low fields to $1152 \pm 545 \mathrm{~kg} \mathrm{DM} \mathrm{ha}^{-1}$ in medium density and to $1839 \pm 825$ in high density fields. Over years of successive cropping with no fertiliser, crop yield first increased between the first and the second year of the cropping cycle followed by a weak trend of yield decline observed as the crop cycle progresses (Fig. 5b).

Table 2

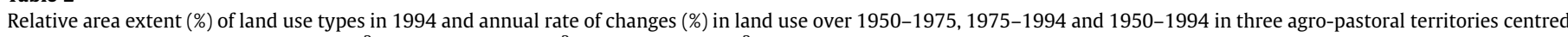

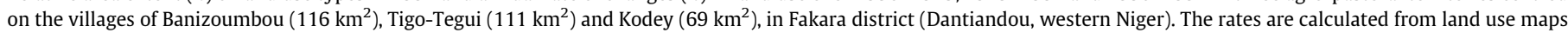
established at the three dates (Hiernaux and Ayantunde, 2004).

\begin{tabular}{|c|c|c|c|c|c|c|c|c|c|c|c|c|}
\hline \multirow[t]{3}{*}{ Village } & \multicolumn{12}{|c|}{ Annual rate of area change over the period (\%) } \\
\hline & \multicolumn{4}{|l|}{ Crop } & \multicolumn{4}{|c|}{ Fallow } & \multicolumn{4}{|c|}{ Rangeland } \\
\hline & $94 \%$ & 50-75 & $75-94$ & 50-94 & $94 \%$ & $50-75$ & $75-94$ & $50-94$ & $94 \%$ & $50-75$ & $75-94$ & 50-94 \\
\hline Bani & 36.2 & 6.5 & 1.5 & 4.4 & 50.4 & 8.3 & 2.1 & 5.6 & 13.4 & -3.1 & -4.6 & -3.7 \\
\hline Tigo & 40.5 & 11.4 & 5.9 & 6.3 & 44.6 & 7.4 & -0.1 & 3.9 & 14.9 & -3.4 & -4.8 & -4.0 \\
\hline Kodey & 65.1 & 7.0 & 2.8 & 2.5 & 25.6 & 3.0 & -0.4 & 0.4 & 9.3 & -7.2 & -1.9 & -5.0 \\
\hline All & 44.6 & 7.7 & 3.3 & 3.9 & 42.4 & 5.8 & 0.0 & 3.3 & 13.0 & -3.6 & -4.5 & -4.0 \\
\hline
\end{tabular}


a

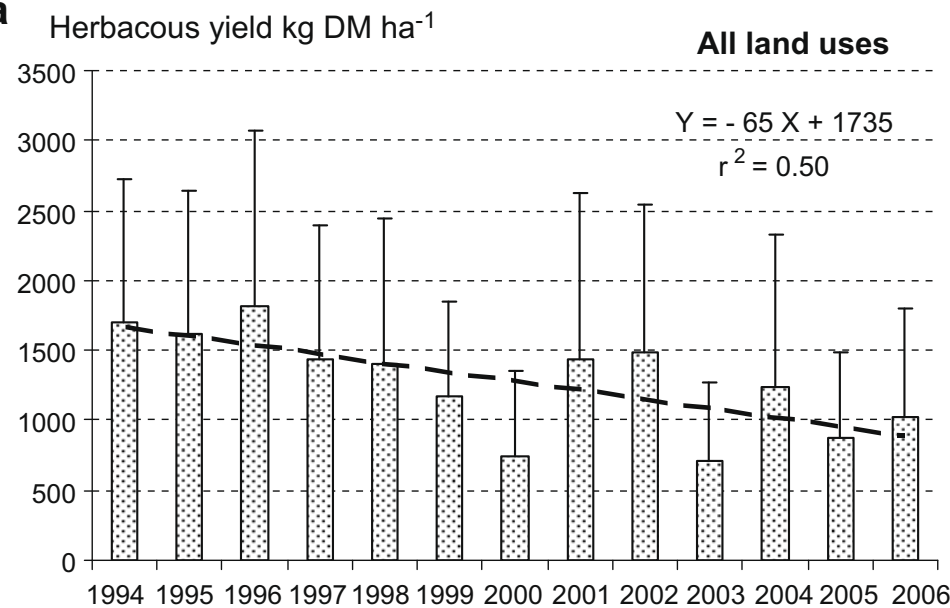

b Herbaceous yield $\mathrm{Kg} \mathrm{DM} \mathrm{ha-1}$

\section{Fallows - Rangelands}

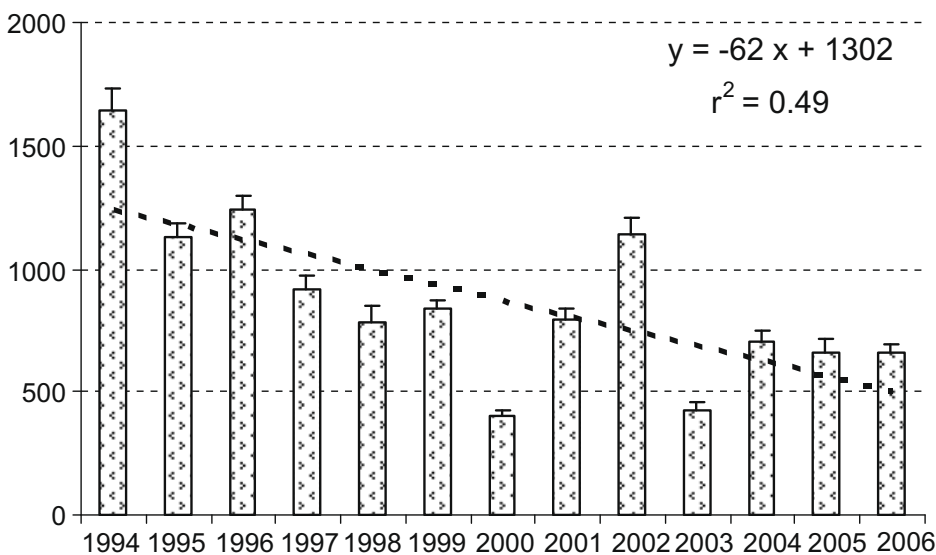

C

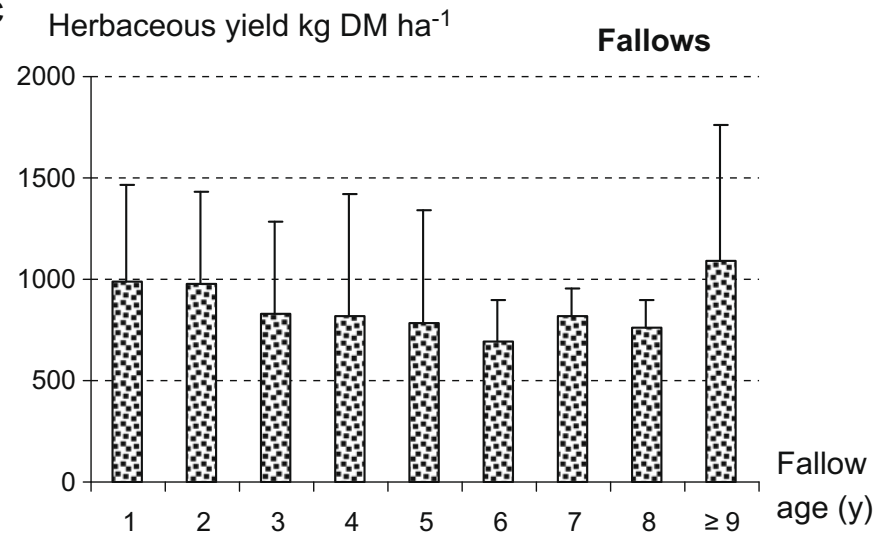

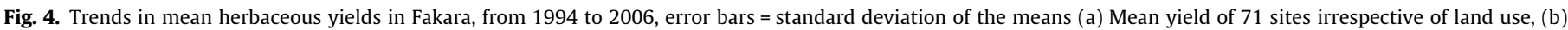
Fallow and rangeland mean yields and (c) Mean yield in fallows as a function of the age of the fallow.

\section{Relationship between herbaceous yields and annual rainfall}

The correlation coefficients of linear regressions between site yield and the annual rainfall measured at the nearest rain gauge were very low when all land use types are considered together, but also when they are calculated by land use (Fig. 6a-c). Similarly, separating fallows and rangelands by soil types did not improve much the correlation. In croplands, weed yields are insensitive to rainfall conditions as expected from the strong dependence on cropping practices. Similarly, the crop yields of fertilised fields were not related to rainfall as expected from their strong dependence on the rate and timing of manure application. The yields of the shifting crop fields were also poorly related to annual rainfall.

\section{Simulating primary production with STEP}

The STEP model was used with the maximum efficiency conversion of photosynthetically active radiation into herbaceous 

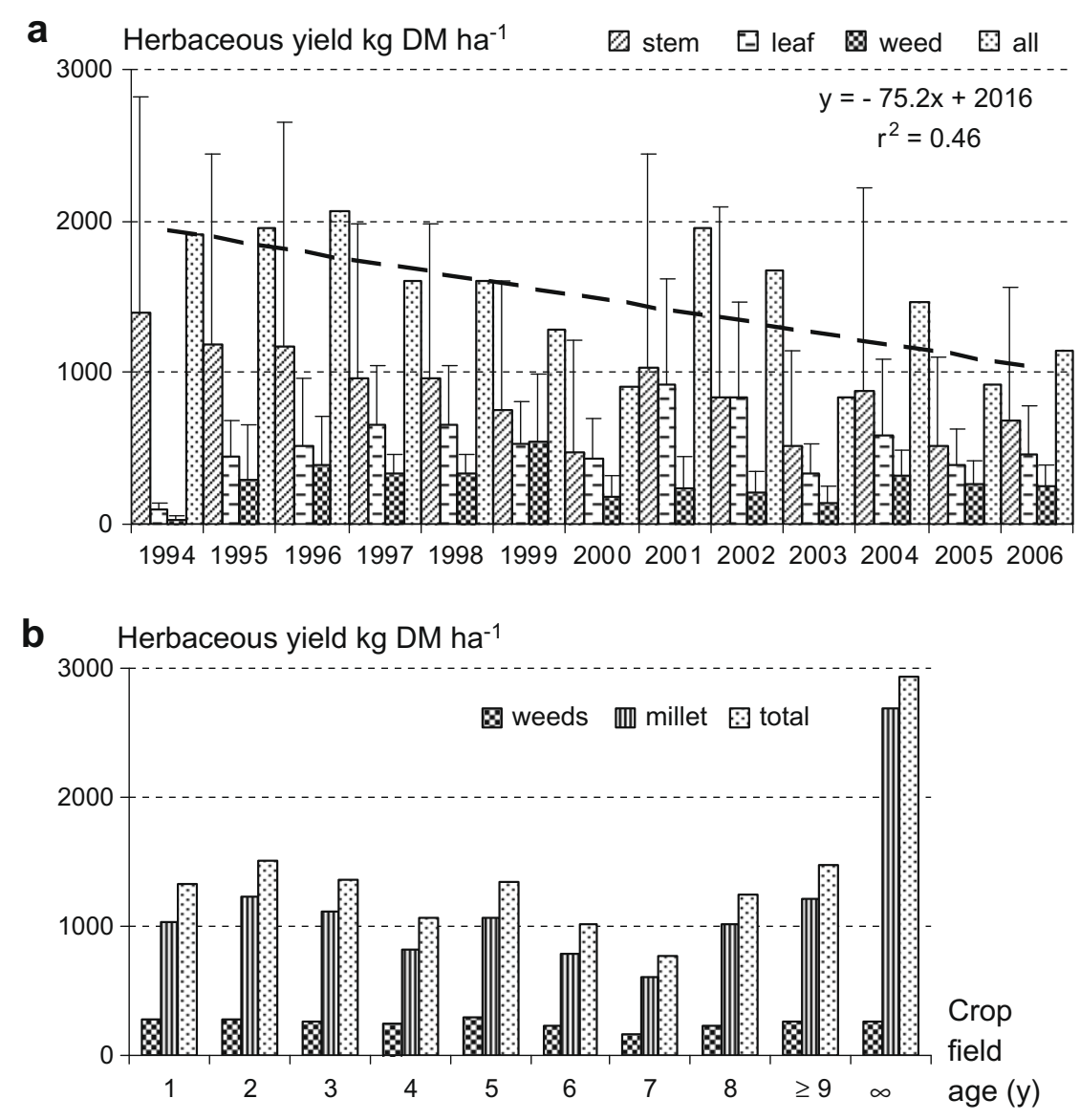

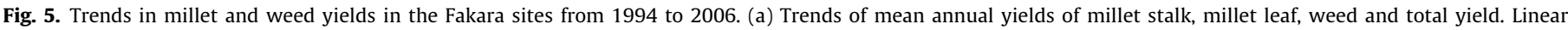

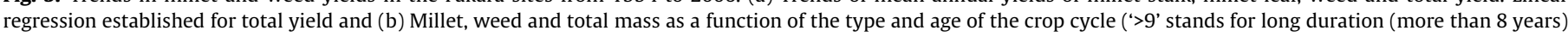
cropping; ' $\infty$ ' stands for permanent cropping implying fertilisation).

mass production $\left(\varepsilon_{0}\right)$ set at $7 \mathrm{~g} \mathrm{MJ}^{-1}$, and the initial standing herbaceous mass resulting from seed germination $(g)$ set at $5 \mathrm{~kg} \mathrm{DM} \mathrm{ha}{ }^{-1}$. The simulated cumulative herbaceous production is poorly correlated to measured yields (Fig. 6d-f). In the absence of simulation of the nutrient control on production in STEP, fixing the maximum efficiency conversion irrespective of soil fertility and also of management (crop genotype, cropping practices, grazing) could explain for the poor correlation observed when all sites are included in the analysis. However, correlations established per land use type or per soil type in the case of fallows and rangelands were also poor. On the other hand, the inter-annual variation of the cumulative production as simulated by STEP, and the herbaceous standing mass measured at the end of the growing season were weakly correlated in some of the sites that remained under fallowing for at least four consecutive years between 2000 and 2006, and were not too intensively grazed throughout the period (Fig. 7). Moreover, simulated production and measured yields generally differ significantly in absolute value. In rangelands, the herbaceous standing mass was largely inferior to simulated production. On the contrary, measured yields in manured croplands largely exceeded simulated production. Differences between measured and simulated yields under shifting cultivation and fallowing were intermediate. In fallows, the simulated production was generally superior to the measured yield. In fields under shifting cultivation, the decrease in yield observed as cropping is repeated over years was not simulated.
Trends in herbaceous species composition in rangelands, fallows and crop fields

\section{Species diversity}

The botanic composition of field sites aggregated by land use type revealed an increase in herbaceous species richness from permanently cropped fields (61 species), to fields under shifting cultivation (97), fallow fields (131) and rangelands (160). Species equitability, other component of species diversity, increased in parallel with richness. Indeed, only four (shifting cultivation) or five (permanently cropped) species contributed to $3 \%$ or more of herbaceous (weeds in cropped fields) cover versus 14 in fallow fields and 12 in rangelands. The three most common species contributed to $72 \%$ of weed plant cover in permanently cropped fields, $71 \%$ in shifting cultivation fields and only to $38 \%$ in fallow fields and $27 \%$ in rangelands.

The contribution to cover of the main species depending on land use

The species that contributed most to herbaceous cover such as Mitracarpus scaber, Cassia mimosoides and Eragrostis tremula, were common to all land use types. The contribution of some species decreased with increasing intensity of land management, as observed for many grasses such as Ctenium elegans and Schoenefeldia gracilis, and for dicotyledons such as Zornia glochidiata (Fig. 8). Conversely, some dicotyledons increased their contribution with increasing management intensity such as Jacquemontia tamnifolia and M. scaber, together with some long cycle annual grasses such as 
a Yield $\left(\mathrm{kg} \mathrm{DM} \mathrm{ha}{ }^{-1}\right)$

All land uses

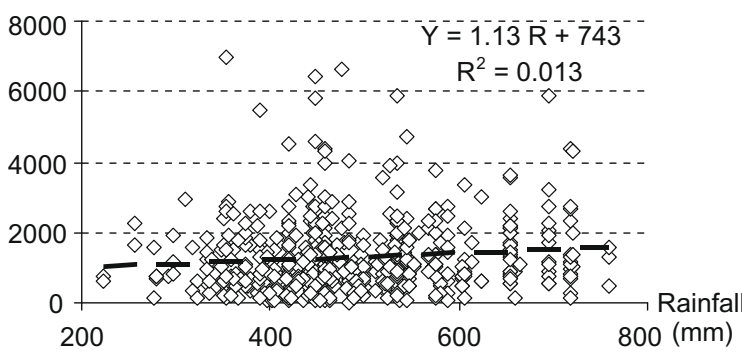

b Yield (kg DM ha-1)

Fallows /soil

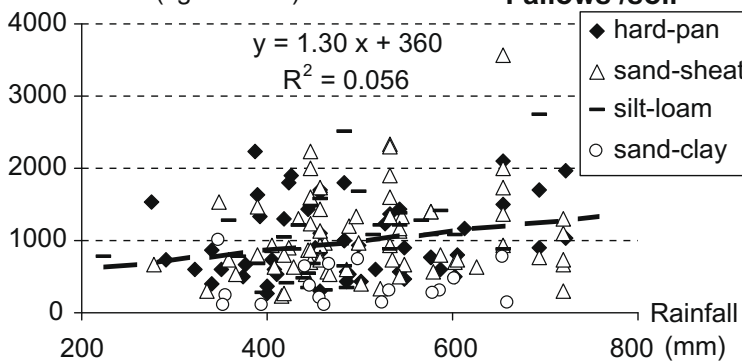

C Yield $\left(\mathrm{kg} \mathrm{DM} \mathrm{ha}{ }^{-1}\right)$

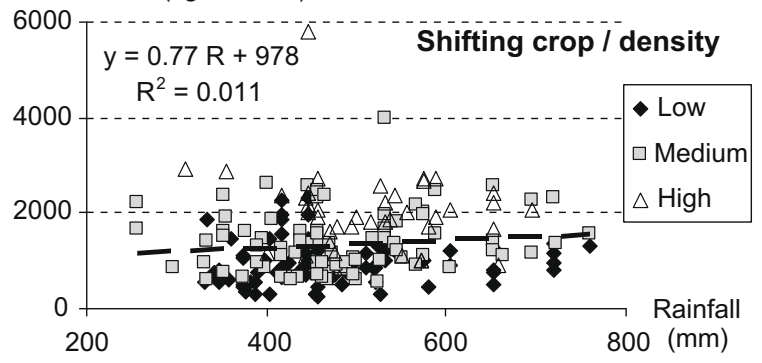

d

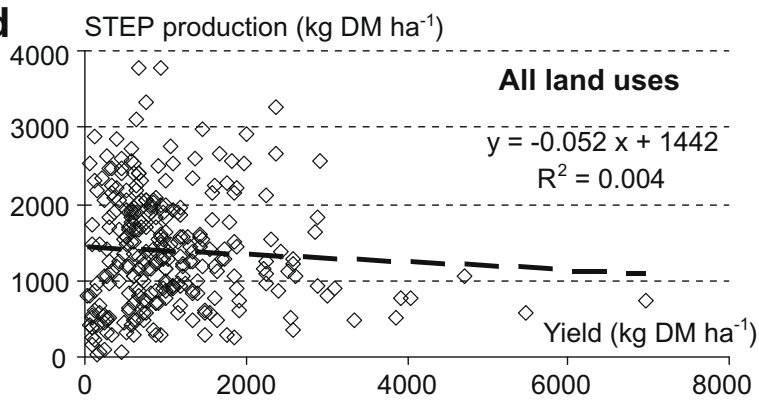

e

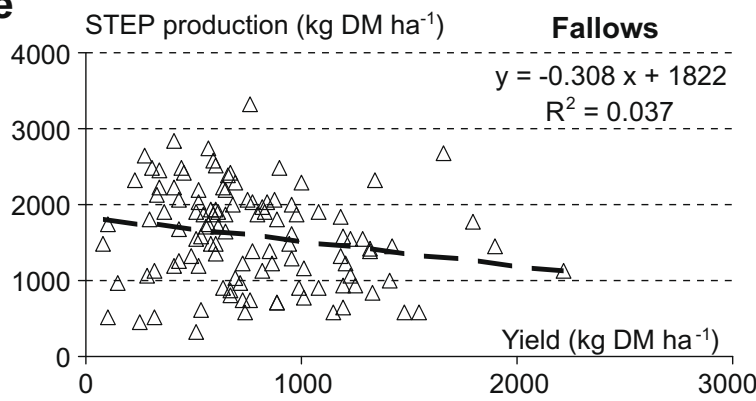

f

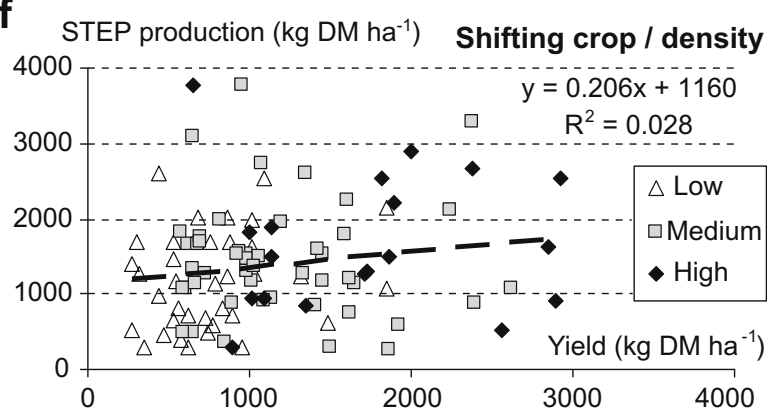

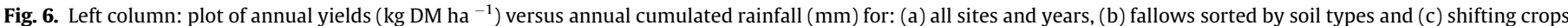

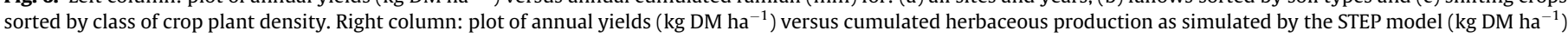
for: (d) all sites and years, (e) fallows and (f) shifting crops sorted by class of crop plant density.

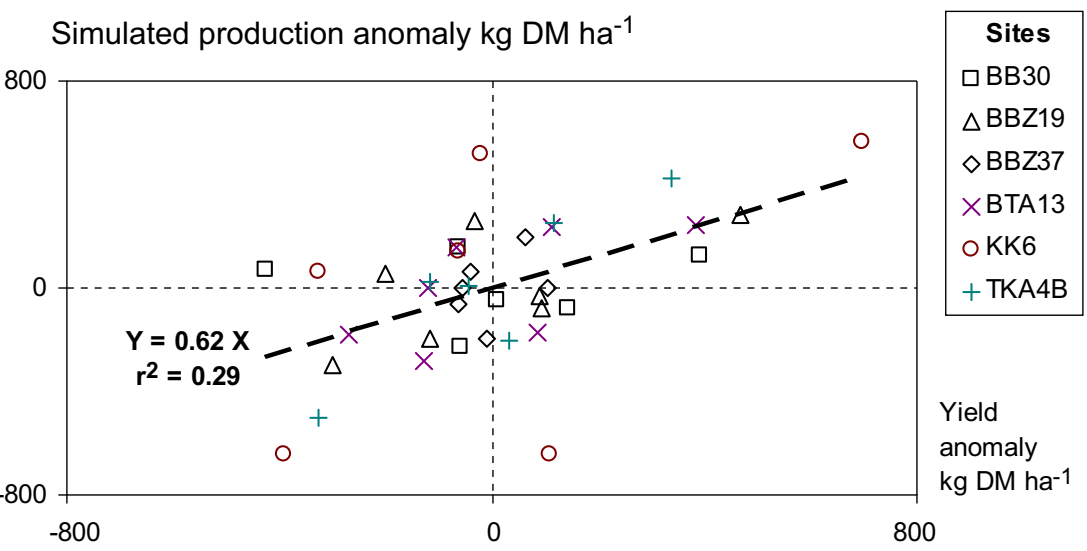



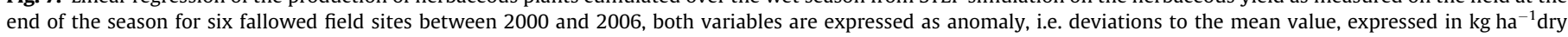
matter.

E. tremula. Among the weeds in cropped fields, the high contribution of dicotyledons such as J. tamnifolia and Commelina forskalei indicated manure application. The absolute values of their contributions varied however largely with years and efficiency of weed- ing. The mass of weeds in fields under shifting cultivation was largely dominated by $M$. scaber, with E. tremula coming second and J. tamnifolia third. The mean contribution of $M$. scaber increased with the age of the field while that of E. tremula decreased 


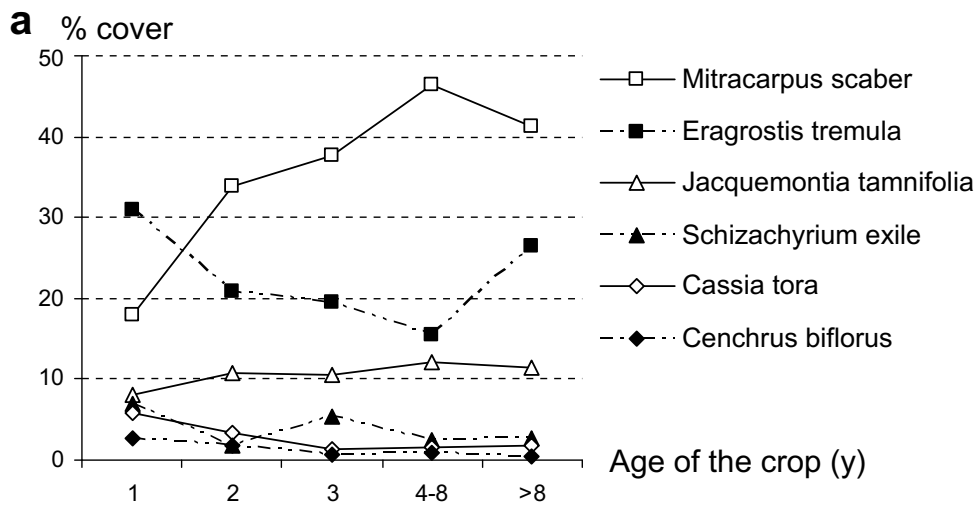

b \% cover

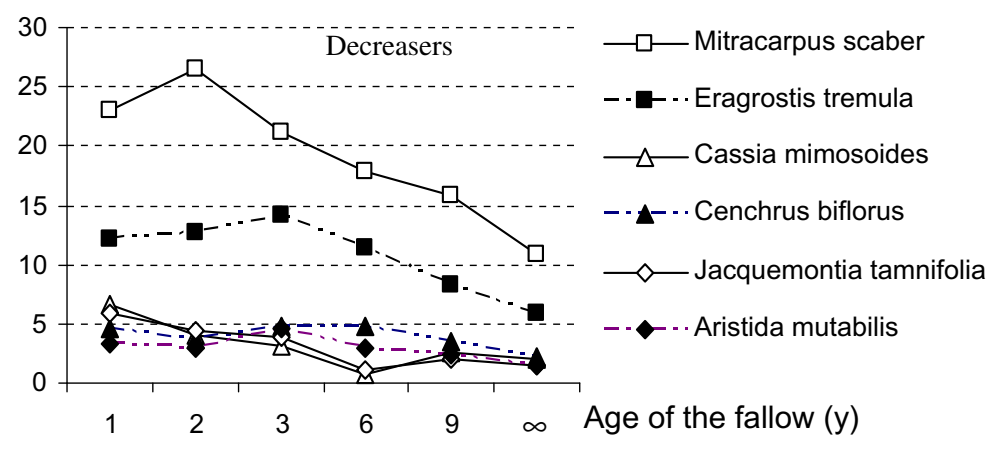

C $\%$ cover

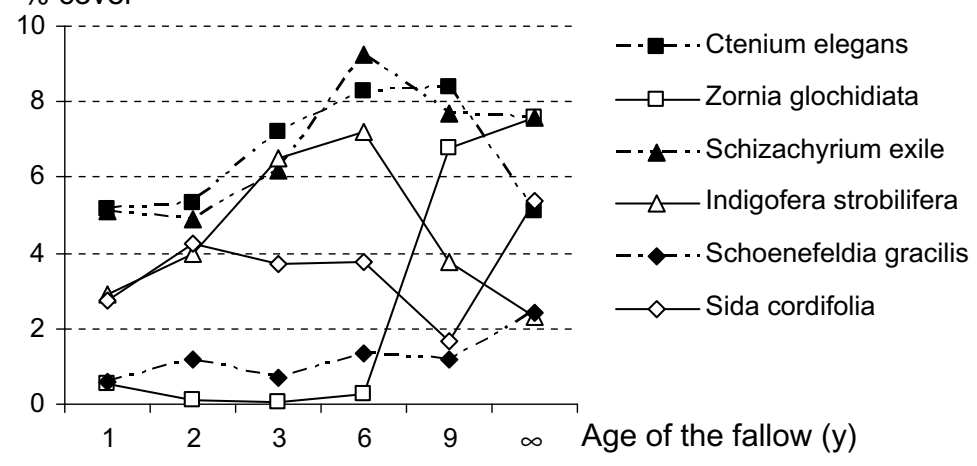

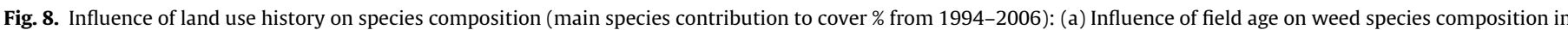

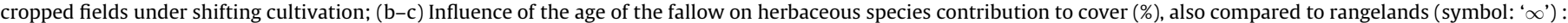
(b) species decreasing contribution as fallow gets older and (c) species increasing contribution as fallow gets older.

(Fig. 8a). There were however large variations of their relative share between sites and years with an overall decrease of $M$. scaber from 1994 to 1999 followed by a sharp increase in 2000. M. scaber contribution to cover remained high since but declined in 2005. $M$. scaber and E. tremula were also the first two contributors to the herbaceous cover of fallows, but they only accounted for $31 \%$ of that cover. They were followed by annual grasses such as C. elegans and Schizachirium exile, two perennial grasses Aristida sieberiana and Andropogon gayanus, and annual legumes such as $Z$. glochidiata and C. mimosoides. The mean contributions of $M$. scaber, E. tremula and C. mimosoides, all main weeds in cropped fields, decreased slowly as fallows were turning older, while most of the other species increase their share, especially the long cycle grass C. elegans (Fig. 8b and c). The species composition of rangelands was more diverse than that of fallows, varying with soil type and the intensity of grazing during the wet season. But even in rangelands, $M$. scaber and E. tremula were among the main contributors accounting for $17 \%$ of herbaceous cover on average (Fig $8 \mathrm{~b}$ ). The other most important contributors to plant cover in fallows were the species whose contribution increases with the age of the fallow such as Z. glochidiata and C. elegans (Fig 8c). Some of these species however were more specific to particular soil types such as Pandiaka heudolotii found on shallow loamy soils, Sida cordifolia and $A$. sieberiana on sandy soils heavily grazed during the wet season. As in other land use types species contributions in rangelands varied largely between sites and from year to year.

\section{Discussion}

Land use

The land use history of the monitored sites gives an indication of the trends in land use over the selected agro-pastoral territories (Fig. 1). However, the land use frequencies recorded across these sites are not representative of the spatial extent of land use types within these territories. The spatial extent of land use types calcu- 
lated from land use maps established by photo-interpretation of aerial photographs (Hiernaux and Ayantunde, 2004) differ between territories (Table 2). Land use drastically evolved over years, and annual rates of change calculated for each land use type, per territory and globally, gauge the historical expansion of the area cropped, though at a decreasing trend. Indeed, the mean annual rate of change in area cropped is $+7.7 \%$ between 1950 and 1975 , with a parallel mean rate of change in area fallowed of $+5.8 \%$, which diminished to $+3.3 \%$ and $0 \%$, respectively, between 1975 and 1994 . The $+2.0 \%$ annual increase in the frequency of crop fields and $1.5 \%$ decrease in that of fallows observed on average between 1994 and 2006 on the 65-71 field sites indicate a further reduction in the rate of crop extension that would be consistent with the historical trend. Stagnation of increase in cropped lands together with an increase in fallowed land area in 2006 (Fig. 2), especially in the more densely cropped territory, Kodey, may be the first indication of a change in land use strategy with farmers abandoning cropping on the marginal land as observed in other Sahelian countries (Tappan et al., 2004; Olsson et al., 2005).

\section{Interannual changes in herbaceous standing mass and production}

Observed separately or all together, herbaceous yields in rangelands, fallowed and cropped fields of one or two hectares in size, are poorly related to mean rainfall over the Fakara sites (Fig. 6). In addition, yield trends of fallow fields and rangelands do not parallel systematically those of cropped fields and follow an overall decrease over the period 1994-2006 (Fig. 4b) which is not explained by mean rainfall. The herbaceous yields of rangelands are very low due to their location on very shallows soils, especially hard pan plateaus. Yet, these rangelands are heavily grazed during the wet season as they often are the only grazing resources left accessible during the cropping season, especially to foreign pastoralists (Turner et al., 2005). Such intense grazing certainly affects the herbaceous standing mass measured at the end of the growing season (Ayantunde et al., 2008). Fallowed fields on the other hand are diversely exposed to wet season grazing depending on their location relative to cropped lands, water points, livestock paddocks and paths. The age of the fallow is expected to have an impact, with soil productivity being low the first years after cropping (Floret et al., 1993). However, the expected increasing trend is not observed in fallow yield (Fig. 4c). On the contrary, the fallow yield tends to be higher the first year after cropping, then stabilises or decreases slightly over the following four years or so, and finally increases in long term fallows as also observed elsewhere in the Sahel (Cissé et al., 1993). The relative high yields observed in the first year could be a positive residual effect on rainwater infiltration of the superficial soil tillage that results from the weeding practiced at least once a year during the crop phase.

The overall superiority of cropped field yields over fallowed field yields mainly results from adapted cropping practices including landrace selection, weeding, soil tillage and fertilisation. Weed yield is only a small component of total cropland yield that does not vary much over years being largely controlled by invested labour and timing of weeding (Hiernaux and Turner, 2002). Indeed, when yields are compared on sites where unfertilised millet crops and fallows alternate, differences in yields between crop and fallow periods are not significant. On the contrary, the yields of permanently cropped and more or less regularly manured fields stand out above that of all other land use types. This yield superiority is partially related to a higher plant density, reflecting the higher sowing density by the farmer who is expecting higher production potential from higher soil fertility (Samaké et al., 2005), but is also due to larger individual plants with more and taller tillers per plant in response to better soil fertility (de Rouw, 1998). The yields of fields under shifting cultivation with no manure application vary largely between fields and years in relation to plant density, sowing and weeding calendar, choice of cultivar and soil amendments, and to inherent soil fertility and uneven distribution of rainfall (Buerkert et al., 2002). Because soil amendment is minimal, a decrease in yield over years of successive cropping would be expected from the progressive depletion in soil nutrients. Indeed, after an initial yield increase between the first and the second year, a weak trend of yield decline is observed as the crop cycle continues (Fig. 5b).

\section{Implications of land use and production dynamics on grazing resources}

Rangelands being confined to non-arable land, the dynamics of grazing resources depends on the trends in relative area cropped or fallowed, and their respective production and feed values. Based on average yields by land use type, the persistent increase of area cropped at an annual rate of $2.0 \%$ accompanied by a decrease of fallowed areas by $1.5 \%$ from 1994 to 2006, translates into an increase of the herbaceous production. However, the shift from fallow to crop also modifies the calendar of access to grazing resources by livestock, as field weeds and millet stalks are only accessible to grazing after grain harvest. The shift thus aggravates the wet season shortage of grazing resources (Ayantunde et al., 2008). It also affects the feed values, as the value of mature weeds and standing or laid down stalks is at most mediocre with Organic Matter (O.M.) content ranging between $89 \%$ and $93 \%$ of dry matter, Crude protein in O.M. ranging between $4.8 \%$ and 9.3\%, O.M. digestibility between $29 \%$ and $63 \%$ of O.M. and metabolisable energy between 6.3 and $8.7 \mathrm{MJ} \mathrm{kg}^{-1}$ O.M. (Savadogo, 2000). Indeed, the prominent weed M. scaber (38\% weed cover) is not palatable, and in millet stalks, only leaf blades and a small fraction of the sheath and stems are palatable to livestock. Hence, the fodder quality of the palatable fraction of millet stalks after harvest scarcely allows livestock to maintain condition with average organic matter of $89 \pm 2 \%$, crude protein concentration of $5.5 \pm 1.0 \%$ and organic matter digestibility of $43 \pm 3 \%$ (Fernández-Rivera et al., 2005). Altogether cropland produced $490 \mathrm{~kg} \mathrm{DM} \mathrm{ha}^{-1}$ of palatable fodder per year, which comes very close to the average $470 \mathrm{~kg} \mathrm{DM} \mathrm{ha}^{-1}$ palatable fodder measured at the end of the growing season in fallows. Thus, increase in area cropped does not affect much the availability of forage over the year, yet it has a major impact on the seasonal access of livestock to quality forage, reducing access to high quality feed during the wet season to the benefit of an access to mediocre quality feed in early dry season.

\section{Relating herbaceous standing mass to cumulative annual rainfall}

Changes in land use of some of the sites during the monitoring period certainly contributed to the poor correlation between herbaceous yield and cumulative rainfall at the nearest rain gauge, but even when land use remained unchanged, the correlations were at best weak. Yet, the distance between field site and nearest rain gauge ( $1.4 \pm 0.7 \mathrm{~km}$ on average with a maximum of $6 \mathrm{~km}$ ), is relatively small compared to the scale of the spatial heterogeneity of rainfall distribution (Ali et al., 2005). Possible discrepancies between the rainfall data used in the analysis and the rains effectively received at a site due to the distance between field site and rain gauge are thus unlikely to explain the poor correlations. Because of the limited number of rain events, with highly variable amount and intensity (Le Barbé and Lebel, 1997), cumulative rainfall over the season does not provide a precise assessment of soil moisture regime and possible plant water stress during the growing cycle (Rockström and de Rouw, 1997). In addition, rainfall is not corrected for run-off and run-on balances that are both-site specific in terms of topography, soil surface features and soil texture and 
the amount, intensity and timing of the rain events (Casenave and Valentin, 1992). Part of the distortion between rainfall and infiltration introduced by the run-off and run-on is scale dependent which is very high at the scale of $1-2$ ha field sites and may tend to average out at the scale of whole watersheds (Estèves and Lapetite, 2003). Moreover, regressing herbaceous yields over cumulative rainfall does not account for the interaction between soil moisture and soil fertility, nor does it account for the unequal ability of plant species to grow and resist stresses and disturbances (Penning de Vries and Djiteye, 1982). On the other hand, the herbaceous standing mass at the end of the growing season underestimates herbaceous production in various proportions depending on the intensity and timing of grazing.

\section{Relating herbaceous standing mass to simulated production}

In sites that remained under fallowing for at least four consecutive years between 2000 and 2006 and were not intensively grazed during wet seasons, the inter-annual variations of the herbaceous production simulated by STEP are in general agreement with the observed inter-annual changes in yields as demonstrated by the weak correlation between site yield anomalies (deviations to the mean) and production simulated anomalies (Fig 7). Correlations between simulated production and measured yields are even poorer in the other situations, including for the four sites that remained as rangeland throughout but are so heavily grazed that the standing mass measured at the end of the growing season reflects poorly actual herbaceous production. However, simulated production and yields differ markedly in absolute terms depending on land use and soil type. Several factors contribute to these discrepancies. On the simulation model side, not modelling the surface redistribution of rain water certainly contributes to underestimation of herbaceous production in flat and low lands and overestimate it on slopes. Non-inclusion of nitrogen and phosphorus provision to plant growth in STEP and fixing the conversion coefficient to a constant, irrespective of site specific soil fertility, has led to large under-estimation of the yields in manured fields and failure to estimate the decreasing trend in crop yield with the age of the field. On the observed production side, the herbaceous standing mass measured at the end of the growing season results from production and also from herbivory removal and decomposition. This could explain why the herbaceous production simulated by STEP that does not account for herbivory, often largely exceeds the standing mass of heavily grazed rangelands and fallows. The multiple causes for discrepancies between simulated production and the end of season standing mass, and their opposite directions, explain for the overall poor correlation, even when sites are sorted by land use or soil type.

\section{Influence of species composition on herbaceous production}

Five species only contribute significantly to weed mass in cropped fields: four C3 dicotyledons and one C4 grass. Although there are weak trends of increase in $M$. scaber (C3 dicotyledon) and decrease in E. tremula (C4 grass) with the age of the field, they do not match with a trend in weed yields. The cropped field yields are driven by the crop yield, with a large dominance of millet and sorghum, two C4 grasses, for which the landraces used in Fakara are highly adapted to the irregular pattern of rainfall during the rainy season: high tillering ability, tall and thick stems and photoperiod sensitivity (Mariac et al., 2006). Total above ground millet yield responds thus well to both soil moisture, and soil fertility as indicated by the wide range of yields measured across the 71 sites. Millet takes advantage of higher soil fertility by tillering more and growing thicker and taller tillers in combination with the high- er plant density set by the farmer (de Rouw et al., 1998; Samaké et al., 2005).

None of the changes in species composition observed in fallowed fields explain the overall decline in fallow yields from 1994 to 2006. Even abrupt switches between the two dominant species, E. tremula and M. scaber in 1995, 1999 and 2005 do not correspond with changes in yields. The gradual changes and enrichment in species composition of fallows as they get older do not explain either the trend of their yield with age. Indeed, the contributions to cover of main dicotyledon, $M$. scaber and main grass, E. tremula, decline as fallows get over three years old, but they are progressively replaced by a mix of grasses and dicotyledons including long cycle annual grasses such as $C$. elegans and $S$. exile, and short cycle dicotyledons such as $Z$. glochidiata.

\section{Conclusion}

The monitoring of 71 field sites sampled across three agro-pastoral territories of the Fakara region from 1994 to 2006 confirmed the continuation from 1994 to 2006 of the historical increase of the area under cropping that started in the mid 20th century, although at a declining annual rate of $2 \%$. This trend does not result from plain area expansion of clearings but from changes in the relative extent of permanently cropped fields and fields under shifting cultivation, and for the latter, from changes in the relative proportion of short versus long duration fallow. The type of land use is determinant for herbaceous production and the resulting herbaceous yield measured towards the end of the wet season. Indeed, average herbage yields range from 3557 to 1548,893 and $221 \mathrm{~kg} \mathrm{DM} \mathrm{ha}^{-1}$ for permanently cropped fields, fields under shifting cultivation, fallow and rangeland respectively. The expansion of the cropped area and the reduction of the fallowed area lead to an increase of the overall herbaceous production (by $2 \%$ annually). However, this increase does not translate into higher palatable feed supply to grazing livestock as only a small fraction of the millet stalks and weeds are palatable. Moreover, between-years within field yield variations are of the same order of magnitude as between site within year variation in yield. From 1994 to 2006, there is an overall decreasing trend by $5 \%$ annually in overall herbaceous yields that is not explained by changes in rainfall. This trend does not affect all sites equally but affects sites among shifting cultivated fields, fallows and rangelands, and has thus likely multiple causes. The expansion of the area cropped over more marginal soils, and also longer duration of cropping periods without fertilisation, together with shortening of the fallowing periods, could all contribute to the decline in yield of shifting cultivated fields. Reduction of fallow duration and increase in wet season grazing pressure on accessible fallowed fields would contribute to herbaceous yield decline of fallowed fields. Finally, the shrinking of rangeland area, only maintained on the most degraded lands, in addition to extreme grazing pressure in the wet season explain yield decline in rangelands. Changes in land use and grazing pressure also triggered changes in species composition with an overall reduction in biodiversity from rangeland to fallow, and further to cropland. No relations were found however between changes in species composition and trends in production.

\section{Acknowledgments}

This work was carried out within the African Monsoon Multidisciplinary Analysis, AMMA, research project funded by a large number of agencies with a major contribution of the European Community‘s Sixth Framework Research Program. Information on AMMA scientific coordination and funding are available on the web site (https://amma-eu.org/). The authors acknowledge the 
International Livestock Research Institute, ILRI, the International Crop Research Institute for Semi-Arid Tropics, ICRISAT, and the Niger Agriculture Research Institute, INRAN, for the data collection and analyses. Farmers and herders from the district of Dantiandou are warmly acknowledged for their hospitality and patience. The authors would also like to thank Dr Teerdj Jan Stomph and an anonymous reviewer who both helped in editing and in narrowing the paper focus.

\section{References}

Ali, A., Lebel, T., Amani, M., 2005. Estimation of rainfall in the Sahel. Part 1: error function. J. Appl. Meteorol. 44, 1691-1706.

Amissah-Arthur, A., Mougenot, B., Loireau, M., 2000. Assessing farmland dynamics and land degradation in Sahelian landscapes using remote sensed and socioeconomic data. Int. J. Geogr. Inf. Sci. 14 (6), S583-S599.

Ayantunde, A.A., Fernandez-Rivera, S., Hiernaux, P.H., Tabo, R., 2008. Implications of restricted access to grazing by cattle in wet season in the Sahel. J. Arid Environ. $72,523-533$

Balme, M., Lebel, T., Amani, A., 2006. Années sèches et années humides au Sahel: quo vadimus? Hydrol. Sci. J. 51 (2), 254-271.

Bielders, C.L., Rajot, J.L., Amadou, M., 2002. Transport of soil and nutrients by wind in bush fallow land and traditionally managed cultivated fields in the Sahel. Geoderma 109, 19-39.

Buerkert, A., Piepho, H.-P., Bationo, A., 2002. Multi-site time-trend analysis of soil fertility management effects on crop production in sub-saharan West Africa. Expl. Agric. 38, 163-183.

Cappelaere, B., Descroix, L., Lebel, T., Boulain, N., Ramier, D., Laurent, J.-P., Le Breton, E., Mamadou, I., Boubkraoui, S., Bouzou Moussa, I., Favreau, G., Issoufou, H.B.A., Nazoumou, Y., Quantin, G., Chaffard, V., Ottlé, C., Boucher, M., (this issue) The AMMA-Catch experiment in the cultivated Sahelian area of south-wes Niger - Strategy, implementation, site description, main results. J. Hydrol., doi:10.1016/j.jhydrol.2008.12.002.

Casenave, A., Valentin, C., 1992. A runoff capability classification system based on surface features criteria in the arid and semi-arid areas of West Africa. J. Hydrol 130, 231-249.

Cissé, M.I., Hiernaux, P., Diarra, L., 1993. Intégration agropastorale au Sahel: dynamique et potentiel fourrager des jachères. In: Floret, C., Serpantié, G. (Eds.). pp. 405-413.

Cottam, G., Curtis, J.T., 1956. The use of distance measures in phytosociological sampling. Ecology 37, 451-460.

de Rouw, A., 1998. Gestion de la fertilité du sol sur un terroir sahélien. Fumure animale, matière organique et encroûtement superficiel du sol dans les systèmes de culture de mil, étude au Niger. Agric. Dévelop. 18, 63-70.

d'Herbes, J.M., Valentin, C., 1997. Land surface conditions of the Niamey region, ecological and hydrological implications. J. Hydrol. 188-189, 18-42.

Estèves, M., Lapetite, J.M., 2003. A multi-scale approach of runoff generation in a Sahelian gully catchment: a case study in Niger. Catena 50, 255271.

Favreau, G. 2000. Caractérisation et modélisation d'une nappe phréatique en hausse au Sahel: dynamique et géochimie de la dépression piézomètrique naturelle du kori de Dantiandou (sud-ouest du Niger). PhD Thesis, Paris XI University.

Fernández-Rivera, S., Hiernaux, P., Williams, T.O., Turner, M.D., Schlecht, E., Salla, A Ayandunde, A.A., Sangaré, M., 2005. Nutritional constraints to grazing ruminants in the millet-cowpea-livestock farming system of the Sahel. In: Ayantunde, A.A., Fernández-Rivera, S., McCrabb, G. (Eds.), Coping With Feed Scarcity in Smallholder Livestock Systems in Developing Countries. ILRI, Nairobi, pp. 157-182.

Floret, C., Pontannier R., Serpantié, G., 1993. La jachère en Afrique intertropicale. Dossier MAB 16. UNESCO, Paris, 86p.

Gandah, M., Bouma, J., Brouwer, J., Hiernaux, P., van Duivenbooden, N., 2003. Optimal allocation of limited nutrient to fields of a Fulani farmer's household in a village in Niger, West Africa. Agric. Ecosyst. Environ. 94, 311-319.

Goutorbe, J.P., Lebel, T., Dolman, A.J., Gash, J.H.C., Kabat, P., Kerr, Y.H., Monteny, B. Prince, S.D., Stricker, J.N.M. Tinga, A., Wallace, J.S., 1997. An overview of HAPEXSahel: a study in climate and desertification. J. Hydrol. 188-189, 4-17.

Guengant, J.-P., Banoin, M., Quesnel, A., 2002. Dynamique des populations, disponibilité en terres et adaptation des régimes fonciers: le cas du Niger, FAO, Rome, 155p

Hiernaux, P., 1998. Effects of grazing on plant species composition and spatial distribution in rangelands of the Sahel. Plant Ecol. 138, 191-202.
Hiernaux, P., Ayantunde, A.A., 2004. The Fakara: a semi-arid agro-ecosystem under stress. Report of research activities, first phase (July 2002-June 2004) of the DMP-GEF programme (GEF/2711-02-4516) ILRI, ICRISAT Centre, Niamey, 95p.

Hiernaux, P., Bielders, C.L., Valentin, C., Bationo, A., Fernandez-Rivera, S., 1999. Effects of livestock grazing on physical and chemical properties of sandy soil in Sahelian rangelands. J. Arid Environ. 41, 231-245.

Hiernaux, P., Turner, M.D., 2002. The influence of farmer and pastoralist management practices on desertification processes in the Sahel. In: Reynolds, J.F., Stafford Smith, D.M. (Eds.), Global Desertification: Do Humans Cause Deserts? Dahlem University Press, Berlin, pp. 35-148.

Hutchinson, J., Dalziel, J.M., 1954-1972. Flora of West Tropical Africa, second edition. In: Keay, R.W.J., Hepper, F.N. (Eds.), vols. 1-3. Crown Agents for Overseas Government and Administration, London.

Le Barbé, L., Lebel, T., 1997. Rainfall climatology of the Hapex-Sahel region during the years 1950-1990. J. Hydrol. 188-189, 43-73.

Lebel, T., Taupin, J.D., D’Amato, N., 1997. Rainfall monitoring during Hapex-Sahel. 1. General rainfall conditions and climatology. J. Hydrol. 188-189, 74-96.

Leblanc, M., Favreau, G., Massuel, S., Tweed, S., Loireau, M., Cappelaere, B., 2008. Land clearance and hydrological change in the Sahel: SW Niger. Global and Planetary Change 61 (3-4), 135-150.

Le Houérou, H.N., 1984. Rain-use efficiency: a unifying concept in arid land ecology. J. Arid Environ. 7, 213-247.

Loireau, M., 1998. Espaces, ressources, usages: spatialisation des interactions dynamiques entre les systèmes sociaux et les systèmes écologiques au Sahel nigérien. PhD Thésis, Montpellier III University, France.

Mariac, C., Luong, V., Kapran, I., Mamadou, A., Sagnard, F., Deu, M., Chantereau, J., Gerard, B., Ndjeuga, J., Bezançon, G., Pham, J.-L., Vigouroux, Y., 2006. Diversity of wild and cultivated pearl millet accessions (Pennisetum glaucum [L.] R. Br.) in Niger assessed by microsatellite markers. Theor. Appl. Genet. 114, 49-58.

Mougin, E., Lo Seen, D., Rambal, S., Gaston, A., Hiernaux, P., 1995. A regional Sahelian grassland model to be coupled with multispectral satellite data. I. Description and validation. Remote Sens. Environ. 52, 181-193.

Olsson, L., Eklundh, L., Ardö, J., 2005. A recent greening of the Sahel - trends, patterns and potential causes. J. Arid Environ. 63, 556-566.

Penning de Vries, F. W. T., Djiteye, M.A., (Eds.), 1982. La productivité des pâturages sahéliens, une étude des sols, des végétations et de l'exploitation de cette ressource naturelle, Pudoc, Wageningen, Agric. Res. Rep., 525p.

Pollard, J.F., 1971. On distance estimators of density in randomly distributed forests. Biometrics 27, 991-1009.

Redelsperger, J.L., Thorncroft, C., Diedhiou, A., Lebel, T., 2006. African Monsoon Multidisciplinary Analysis (AMMA): an international research project and field campaign. Bull. Am. Meteorol. Soc. 87 (12), 1739-1746.

Rockström, J., de Rouw, A., 1997. Water, nutrients and slope position in on-farm pearl millet cultivation in the Sahel. Plant Soil 195, 311-327.

Samaké, O., Smalling, E.M.A., Kropff, M.J., Stomph, T.J., Kodio, A., 2005. Effects of cultivation practices on spatial variation on soil fertility and millet yields in the Sahel of Mali. Agric. Ecosyst. Environ. 109 (3-4), 335-345.

SAS 1987. SAS/STAT for personal computers. SAS institute, Cary, NC, 1027pp.

Savadogo, M., 2000. Crop residue management in relation to sustainable land use. A case study in Burkina Faso. Trop. Res. Manage. Paper, 31, Wageningen University, 159p.

Schlecht, E., Hiernaux, P., Achard, F., Turner, M.D., 2004. Livestock related nutrient budgets within village territories in western Niger. Nutr. Cycl. Agroecosyst. 68, 199-211.

Schlecht, E., Hiernaux, P., Kadaouré, I., Hülsebusch, C., Mahler, F., 2006. A spatiotemporal analysis of forage availability and grazing and excretion behaviour of herded and free grazing cattle, sheep and goats in Western Niger. Agric. Ecosyst. Environ. 113, 226-242.

Tappan, G.G., Sall, M., Wood, E.C., Cushing, M., 2004. Ecoregions and land cover trends in Senegal. J. Arid Environ. 59 (3), 427-462.

Tracol, Y., Mougin, E., Jarlan, L., Hiernaux, P., 2006. Testing a sahelian grassland functioning model against herbage mass measurements. Ecol. Model 193, 437446.

TropSoils, 1991. Integrated management of agricultural watersheds (IMAW). Characterization of a research site near Hamdallaye, Niger. TropSoils Bulletin 91-03, Soil Management CRSP, Raleigh, USA, 109p.

Turner, M.D., 2000. Drought, domestic budgeting, and changing wealth distribution within Sahelian households. Develop. Change 31, 1009-1035.

Turner, M.D., Hiernaux, P., Schlecht, E., 2005. The distribution of grazing pressure in relation to vegetation resources in semi-arid West-Africa: the role of herding. Ecosystems 8 (6), 668-681.

White, N.A., Engeman, R.M., Sugihara, R.T., Krupa, H.W., 2008. A comparison of plotless density estimators using Monte Carlo simulation on totally enumerated field data sets. BMC Ecol. 8 (6), 11 